\title{
Flow Experience and Self-Traits as Antecedents of Facebook Addiction: Factorial Validity of the Daily Facebook Addiction Scale
}

\author{
Tsai-Wei Huang ${ }^{1}$, Guan-Han $\mathrm{Wu}^{2}$, \& Han-Chao Chang ${ }^{3}$ \\ ${ }^{1}$ School of Nursing, College of Nursing, Taipei Medical University, Taipei, Taiwan \\ ${ }^{2}$ National Taiwan Normal University, Taipei, Taiwan \\ ${ }^{3}$ National Applied Research Laboratories, Hsin Chu, Taiwan \\ Correspondence: Han-Chao Chang, National Applied Research Laboratories, Hsin Chu, Taiwan.
}

Received: August 18, 2018

Accepted: September 10, $2018 \quad$ Online Published: December 6, 2018

doi:10.5539/ibr.v12n1p1

\author{
URL: https://doi.org/10.5539/ibr.v12n1p1
}

\begin{abstract}
Facebook has become indispensable in social interactions. Unmarried users may find a date or life partner by uploading attractive photos of themselves or messaging their crushes. This study developed the Daily Facebook Addiction Scale (DFAS), which focuses on using mobile devices to access Facebook. The aims were explored how flow experience is created based on the self-traits of Facebook users and analyzed the relationship between flow experience and Facebook addiction. Data was obtained 401 participants through the Internet, in total, 231 were addicted to Facebook, that is, they accessed it for $>2$ hours a day. This study indicated: (1) users' concentration and interactivity had a positive effect on creating flow experience but enjoyment did not. (2) Respondents' flow experiences had a significant effect on Facebook addiction. (3) The subfactors of a respondent's self-traits individually had positive effects on flow experience and Facebook addiction, and self-control generated the most significant effect. Three antecedents, namely self-traits, flow experience, and Facebook addiction, do indeed affect each other.
\end{abstract}

Keywords: flow experience, self-traits, Facebook addiction, Daily Facebook Addiction Scale (DFAS)

\section{Introduction}

Social sites, such as LinkedIn, Facebook, and Chameleon Social, have their own unique styles and followers. Users can make friends, share photos, make calls, and even find jobs using short text messages (Sledgianowski et al., 2009) or free voice over Internet protocol video calls. According to a survey by Luchini (2015), 50\% of 18-24 year olds access Facebook when they wake up in the morning; 510 comments are posted, 293,000 statuses are updated, and 136,000 photos are uploaded on Facebook every 60 seconds. Thus, visiting a social website daily to check one's interactions with other users and messaging or calling other users has become an integral part of everyday life.

With a higher frequency of Facebook use, an individual has a higher probability of becoming addicted (Echeburúa et al., 2010; Gonidis et al., 2017; Kuss et al., 2011; Luchini, 2015). In Facebook addiction studies, students' self-traits, flow experience, learning achievement, weekly sign-in frequency and usage cycle, and addictive symptoms are the most frequently researched subjects (Andreassen et al., 2012; F. Y. Hong et al., 2014; Koc et al., 2013; Pelling, 2009; Wilson et al., 2010). However, the relationships between users' self-traits, flow experiences, and levels of Facebook addiction is still unclear. Therefore, this study wanted to investigate their self-traits, exploring why flow experience is created by a questionnaire with a Daily Facebook Addiction Scale (DFAS).

\section{Social Networks and Facebook}

Barnes (1954) was the first to conceive the concept of social networks. He viewed social networks as crystals composed of unit cells, which constituted individuals or organizations. These unit cells are connected through various social familiarities, including family, friends, friend's friends, and even strangers. After Barnes' study, many studies were conducted in the area of social networks. Recently, this type of research has become a new field of social science, namely computational social science. The advent of computers and social media changed the way interpersonal contact is established in social networks as compared with that during Barnes' study. User interactions on social networking sites are different from those in the real world. Web forums let users leave 
comments in a forum to discuss common topics. The online community is composed of users in virtual forums establishing relationships through emails. This method of communication is similar to web-based social networks (Adamic et al., 2003). Golbeck (2005) believes that users of web-based communities must establish clear relationships with others where both parties can browse each other's messages. Both Twitter and Facebook belong to this type of community. To use Facebook, users register by creating an account and a password. They have access to a personal message board and can edit personal data, such as name, gender, location, experience, and biography. Personal profiles also include a personal photograph. Users can upload their own photos and use media to create a personal brand. Facebook users can visit their own page and their friends' pages to interact with them by leaving messages and writing to each other.

In addition, Kuss and Griffiths (2011) found that addiction to social networks on the Internet may result in health problems for users; the long-term use of social networking sites may result in poor academic performance and relationship problems. Insomnia and short-term sleep have been common symptoms of Internet addiction in this decade (Bruning et al., 2010; Dewald et al., 2010). Echeburúa and de Corral (2010) believe users addicted to social networking sites experience symptoms similar to people with physical addictions, such as caffeine or nicotine, or behavioral addictions. La Barbera et al. (2009) inferred that younger users with impressionable minds or those with narcissistic tendencies are particularly susceptible to addiction.

Pelling's (2009) research on Facebook addiction and social networking addiction, which involved 233 students, showed that users of social networking sites $\log$ in to networking sites at least four times a day. Social networking sites help them gain self-identity and a sense of belonging, which may present unnecessary risks for addiction. The study of Wilson et al. (2010) on social networking addiction, which involved 201 students, suggested that highly extroverted users with low self-esteem are more likely to become addicted and spend excessive time on social networking sites. Extroverted users become addicted because they require social interaction, and people with low self-consciousness become addicted because they have lower-than-average self-control. Karaiskos et al. (2010) gave the example of a woman who was addicted to social networking websites, which caused her to spend at least 5 hours a day on such websites during which she would update her status repeatedly. Her addiction lead to her getting fired from her job and also induced symptoms of anxiety and insomnia.

Therefore, Andreassen et al. (2012) developed the Bergen Facebook Addiction Scale (BFAS) and Online Sociability Scale (OSS) by combining the addiction scale from Brown (1993) and Griffiths (2000), diagnostic criteria for pathological gambling, and the game addiction scale (Park et al., 2009) to measure the degree of Facebook addiction. A study on 423 college students without prior expert validation found that these two scales can measure Facebook addiction. A participant's addiction was found to be negatively related to that participant's sleep quality and conscientiousness. Koc and Gulyagci (2013) developed a Facebook Addiction Scale to measure 447 Turkish college students' weekly usage of Facebook. They discovered that most students averagely spent 15 minutes per week within 7 hours, and desktop computers at home or in dormitories were still the main type of device used to access Facebook. The study results also indicate that time spent on Facebook weekly and insomnia could positively predict a college student's Facebook addiction. Hong et al. (2014) modified an Internet addiction scale into a mobile phone addiction scale for determining Facebook addiction. Relative to the average Facebook user, college students are unusually likely to use mobile phones to access Facebook, students who have depressive personalities may access Facebook often.

Csikszentmihalyi (1975), the scholar who proposed the concept of flow experience, believes that flow is a comprehensive experience that each individual actively participates in voluntarily without thinking about reward or punishment while focusing on his or her topic of interest or work. Csikszentmihalyi and Massimini (1985) measured the flow experiences of 208 adolescents in their daily lives under four different situations: at school, with family, with friends, and in solitude. They discovered two main things: (1) skill and challenge are the main factors that lead to the best experiences, but concentration leads to a more complete flow; and (2) no limits exist. After Csikszentmihalyi and Moneta proposed characteristics that lead to flow experience, Koufaris (2002) and Skadberg and Kimmel (2004) agreed that satisfaction is a key element for achieving flow. Choi et al. (2007) used a computer as a medium for personal flow study and divided flow into three stages: (1) flow antecedents, or the factors needed for immersion or satisfaction; (2) flow experience, or the characteristics experienced during the flow; and (3) flow consequences, or the effect of flow experience on the individual. This study also integrated the study results of Hoffman and Novak (2009) and Esteban-Millat et al. (2014), their constructs of flow and flow research results based on flow antecedents, flow experience, and flow consequences. The findings of this study are as follows: (1) flow experience is a continuous and dynamic process, which changes according to a person's habits, traits, and life experiences; (2) the process undergoes different stages from flow antecedents to 
flow experience to flow consequence; and (3) flow consequence differs according to the individual situation.

Regarding studies on flow antecedents, both Koufaris (2002) and Skadberg and Kimmel (2004) agree that prior satisfaction factors must be in place before flow can be achieved. Enjoyment and concentration are two antecedents for achieving flow and measuring consumer intention for continual online shopping. Pearce et al. (2005) used enjoyment and concentration as flow antecedents to measure the performance of university students in online learning exercises. Siekpe (2005) used four antecedents, namely concentration, control, challenge, and curiosity, to assess the online shopping behaviors of 2,500 Americans. Steuer (1992) and Webster and Martocchio (1992) have used interactivity as an antecedent for human-computer web interaction in their research of Internet flow experience. They believe that interaction is an uncommon channel of communication, which exists between users in the field of human-computer interaction. Therefore, this study has selected the most commonly discussed antecedents, namely enjoyment, concentration, and interactivity, to analyze the flow experience of unmarried Facebook users.

Khang et al. (2013) believe that self-traits are based on observation of other's behavior or social events, or discovery of one's personality and characteristics through interactions in interpersonal relationships. Therefore, one can use evaluation of self, belief in self, and control of self to assess a person's traits. For exploring digital media addiction, studies have used self-traits such as self-esteem, self-efficacy, and self-control as antecedents of media addiction (Baumeister, 1999; Khang et al., 2012; H. K. Kim et al., 2009). Rosenberg (1965) believes that self-esteem usually refers to a person's evaluation of himself or herself, which involves both slightly positive and slightly negative views. Social psychologists believe that people can evaluate whether they have antisocial behaviors or psychological disorders by examining their own self-esteem (Baumeister, 1999; Kernis, 1993; Rosenberg, 1965). Many studies have discovered that, in general, people with low self-esteem may participate in antisocial activities to prove that their self-esteem levels are higher than the levels of those who do not participate. People with high self-esteem exhibit a high level of self-confidence regardless of circumstances. Because those with high self-confidence can cope with external pressures and deal with problems appropriately, the probability of them exhibiting instability or a sense of inferiority is low.

According to Gist and Mitchell (Gist et al.), self-efficacy is a person's level of confidence in his or her ability to successfully complete a task. A person's judgement goes through a process of organization, planning, implementation, and achievement of a specific goal, and that process can be interpreted as self-efficacy (Bandura, 1997; Gist \& Mitchell, 1992; Zimmerman, 2000). Bandura (1997) argues that an individual's cognitive process is related to his or her personal expectation of performance and may affect the selection of his or her end goal. In other words, self-efficacy can affect a person's ability to cope and deal with potential obstacles or negative experiences. Therefore, self-efficacy can directly or indirectly affect a person's levels of anxiety, stress, and stubbornness (Bruning et al., 2010).

Self-control involves an individual's ability to control and resist his or her own inner desires through self-control and achieve better results than originally envisioned (Tangney et al., 2004). Individuals with high self-control have high motivation to achieve goals and considerable ability to adjust their own lifestyles. For example, those with high self-control are not likely to overeat or abuse alcohol. Additionally, these people have relatively good interpersonal relationships and communication techniques. Furthermore, they come up with relatively good strategies and consider the overall situation in the face of difficulties (Tangney et al., 2004). Conversely, individuals with low self-control have a strong and serious dependency on their own emotional tendencies. Thus, they are prone to reckless behaviors, short-sighted judgments, and undisciplined or lazy behavior (Zimmerman, 2000). Therefore, this study explores self-esteem, self-efficacy, and self-control and their relationships with Facebook addiction.

\section{Research Framework and Hypotheses}

Social sites, Flow experience is a measure of the degree of investment an individual has toward someone or something. When users are completely involved in an activity, they lose their sense of self. Typically, people maintain a sense of self-awareness about their image, but in flow experience, they temporarily lose their sense of self-defense. Because immersion in an activity occupies the entirety of a person's mind and thoughts, all other thoughts are neglected. In many flow-experience studies, scholars have considered multiple factors as antecedents leading to flow. This study measures the effect of immersion-experience antecedent-enjoyment, concentration, and interactivity — on a Facebook user's flow experience.

Merhi (2016) pointed out a positive effect of enjoyment on flow experience in his study on online gaming. In day-to-day life, most of the activities we engage in involve external feedback, and the goal of these external feedback activities is typically not spontaneity. However, from the flow-experience perspective, when people are 
engaged in activities of a more spontaneous nature, they feel an intrinsic motivation because these activities are inherently interesting, provide a feeling of happiness, and carry enough motivating force for execution. When an individual chooses to participate in an activity spontaneously, external feedback and motivation are no longer considerations as intrinsic motivation replaces these factors. For example, mountain climbing has an external goal, namely reaching the top. However, mountain climbers who disregard the external goal may climb spontaneously and enjoy the activity of climbing for its own sake. From a psychological perspective, Koufaris (2002) posited that the entertainment value of flow experience is an intrinsic enjoyment, similar to feelings and reactions of joy. Moreover, this activity becomes enjoyable in a comfortable environment and when it changes from nonspontaneous to spontaneous.

When people become absorbed in an activity or a purposeful task, their effort and attention are totally focused on that activity, and even the smallest detail is given considerable attention. Furthermore, any previous concerns unrelated to the activity are forgotten or overlooked (M. Csikszentmihalyi, 1990). Koufaris (2002) believes that a person's focus must be harnessed on the current activity before he or she enters a flow state, and he observed focus as one of the measures of flow experience. He also pointed out that the antecedent's enjoyment and concentration showed a positive effect on flow experience. Pearce et al. (2005) also measured flow experience using enjoyment and concentration; their results showed a positive correlation between these two antecedents and flow experience. Hong et al. (2013) also used antecedents such as enjoyment and concentration to measure the effect instructional games had on a student's flow experience; their results showed a positive effect as well. Yang et al. (2014) studied the benefits and dangers of flow experience in high school students' Internet usage; their results show that enjoyment and concentration have positive effects on flow experience.

Webster and Martocchio (1992) argued that the interactivity between people and machines is another crucial factor, which could be interpreted as an enjoyable or exploratory experience. Moreover, Steuer (1992) defined interaction as "the extent to which users can immediately participate in and change the content of the intermediary communication environment." He further stated that interactivity is the feedback generated from the interplay between users; the speed of this interplay also contributes to the quality of the interactivity. Su et al. (2016) incorporated both human-computer interactivity and social interactivity in their research on mobile game application; their results show that both human-computer and social interactivity have positive and significant effects on flow experience.

Novak et al. (1998) and Webster (1992) have demonstrated interactivity as one of the most essential factors for immersive human-computer interaction. Their research used interactivity as an antecedent of flow experience, and the results show that the interactive behavior of users while browsing enhanced their flow experience and made the users feel immersed. Thus, interactivity is highly related to flow experience and the two have a high positive correlation. Skadberg and Kimmel's (2004) study demonstrated positive effects of interactivity on web browsing and flow-experience accumulation. Thus, interactivity may enhance the quality and quantity of network flow experience, and the two share a strong correlation, especially in situational interaction and message interaction. Therefore, this study proposed the following hypotheses:

$\mathrm{H}_{1}$ : Enjoyment has a significant positive effect on a Facebook user's flow experience.

$\mathrm{H}_{2}$ : Concentration has a significant positive effect on a Facebook user's flow experience.

$\mathrm{H}_{3}$ : Interactivity has a significant positive effect on a Facebook user's flow experience.

Self-traits can be interpreted as a person's ability to control his or her own actions or emotions, or a person's ability to deal with things. People with low self-traits tend to have less control over their own actions compared with those with high self-traits, and thus, self-traits affect flow and addiction (Khang et al., 2013; E. J. Kim et al., 2008). Khang et al. (Khang et al., 2013; Khang et al., 2012) studied the influence of a user's self-traits on their level of flow and addiction to digital media, such as the Internet, mobile phones, and video games. Their results show that a user's self-traits, namely self-esteem, self-efficacy, and self-control, show effects on both flow and addiction.

Many researchers have used self-esteem, self-efficacy, and self-control to evaluate self-characterization and explore the effects of self- perception on flow and addiction (Khang et al., 2013; Khang et al., 2012) . First, people with high self-esteem are not easily influenced by their external environment and emotions. Particularly, people who are psychologically healthy have higher-than-average self-esteem; they believe that they have value and deserve to be respected by others. Additionally, these people are willing to accept their own shortcomings. For example, people with high self-esteem are not bothered by their self-tolerance or other people's persuasion or accusations (Brown, 1993). Second, self-efficacy is an individual's judgment, belief, confidence, and feeling of whether he or she has the ability to complete an activity above certain standards (Maibach et al., 1995). Self-efficacy plays a role in a person's ability to make decisions regarding behavioral tasks and to regulate 
concentration and effort needed in a task. Self-efficacy also affects mental processes and emotional reactions while completing the task. Third, self-control is an individual's active dominance over behavior and mindset; it is a human-specific activity (Baumeister, 1999). People display a high degree of satisfaction when they can control their own leisure activities; however, in a situation of leisure, overall self-control is relatively low because when numerous leisure activities are needed to satisfy a person, the number of things that he or she can control declines (Tangney et al., 2004).

Individual differences determine how prone people are to experience flow in daily life (de Manzano et al., 2013; Mosing et al., 2012; Ullén et al., 2012; Un et al., 2010). These differences are likely to depend on both individual self-traits and situational variables (Ullén et al., 2012). Flow is a state of high attention to tasks and a sense of action automaticity, but it differs subjectively from mental effort in that concentration feels effortless (Mihaly Csikszentmihalyi et al., 2010). Positive association has been reported between flow experiences and self-traits in low neuroticism (stability), e.g. active coping strategies, psychological well-being, and a sense of high control (Mihaly Csikszentmihalyi \& Nakamura, 2010; Mosing et al., 2012; Ullén et al., 2012; Un et al., 2010). Moreover, flow proneness is positively related to self-esteem, self-concept, psychological well-being, and a tendency to adopt active rather than passive coping strategies (Mosing et al., 2012; Ullén et al., 2012).

Flow experience has been found to have a positive effect on addiction (Gentile et al., 2017; F. Y. Hong et al., 2014; Khang et al., 2013). Flow experience refers to being very focused on one activity. The more interested one is in an activity, the more immersed one becomes in flow experiences, which often leads to addiction. The activities and objects that lead to addiction through flow experience include online gaming, Internet browsing, smart devices, and video games (Khang et al., 2013; B. Kim, 2006; Park \& Hwang, 2009). Su et al. (Su et al., 2016) showed a positive and significant effect of flow experience on player loyalty in mobile game applications. Khang et al. (2013) and Yang et al. (2014) have showed that flow experience has a positive and significant effect on Internet addiction. Hong et al. (2014) modified an Internet addiction scale into a mobile phone addiction scale to determine Facebook addiction and showed that Facebook usage has a positive and significant effect on Facebook addiction in university students. Therefore, this study proposed the following hypotheses:

$\mathrm{H}_{4}$ : A Facebook user's self-traits have a significant positive effect on flow experience.

$\mathrm{H}_{4 \mathrm{a}}$ : A Facebook user's self-esteem has a significant positive effect on flow experience.

$\mathrm{H}_{4 \mathrm{~b}}$ : A Facebook user's self-efficacy has a significant positive effect on flow experience.

$\mathrm{H}_{4 \mathrm{c}}$ : A Facebook user's self-control has a significant positive effect on flow experience.

$\mathrm{H}_{5}$ : A Facebook user's self-traits have a significant positive effect on Facebook addiction.

$\mathrm{H}_{5 \mathrm{a}}$ : A Facebook user's self-esteem has a significant positive effect on Facebook addiction.

$\mathrm{H}_{5 \mathrm{~b}}$ : A Facebook user's self-efficacy has a significant positive effect on Facebook addiction.

$\mathrm{H}_{5 \mathrm{c}}$ : A Facebook user's self-control has a significant positive effect on Facebook addiction.

$\mathrm{H}_{6}$ : A Facebook user's flow experience has a significant positive effect on Facebook addiction.

\section{Research Method}

The study was designed to target unmarried Facebook users who log in using mobile devices. The framework of this study is shown in Figure 1. The survey was conducted using SurveyMonkey online questionnaires, and respondents were selected using purposive sampling. Before the survey, the first question is to ask the informed consent. After the surveys had been completed, the respondent clicked on the submit button; the information was stored in the server's database. The SurveyMonkey software checked for missing answers, and if any answers were missing, the results were not sent to the database. The email IDs of the respondents were entered into a lucky draw to motivate the respondents to complete the survey and thus improve sample recovery rate.

To ensure instrument validity, all items were adapted from the extant literature. Andreassen et al. (2012) developed the BFAS and OSS to measure user addiction. The BFAS contains five levels of frequency: (1) very rarely, (2) rarely, (3) sometimes, (4) often, and (5) very often. The OSS uses nine periodic anchors ranging from 1 (less than once per year) to 9 (more than once daily) to measure usage. Andreassen et al.(2012) carried out their original Facebook addiction research when most users would log in to Facebook using desktop computers; hence, their frequency of use and usage cycle were very different from those of present users. Currently, most users log in using smart devices with $4 \mathrm{G}$ networks when outdoors and use desktop computers only when they are at home or office. The probability of a user becoming addicted may be greater than that in 2012 . Therefore, this study developed the Daily Facebook Addiction Scale (DFAS), which consists of (1) <30 minutes, (2) 31-60 minutes, (3) 1-2 hours, (4) 2-3 hours, (5) 3-4 hours, and (6) >4 hours, to measure Facebook addiction in mobile device users. 


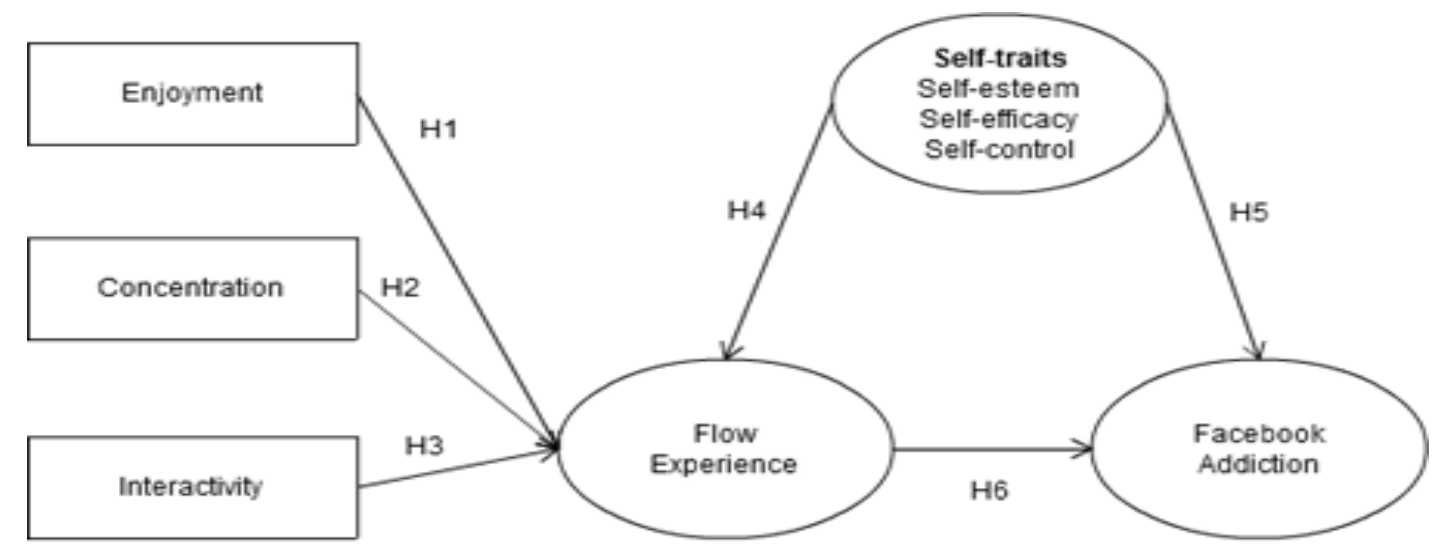

Figure 1. Framework of this study

This study collected 200 sets of valid responses as pretest data using an online questionnaire. This study used an Item Analysis (or Item Discrimination Analysis) method to analyze the pretest data by using SPSS 20 statistical software. The primary purpose of the item analysis was to determine an individual item's critical ratio, or composite reliability (CR) value, to eliminate items that do not meet standards. Eliminating items that hold no discrimination for the data can improve validity and reliability of the questionnaire in advance. All items were statistically significant, except for self-trait items SEM2, SEY2, and SEL1 and Facebook addiction item SNA16 ( $\mathrm{p}<0.001)$. The homogeneity test revealed that self-trait items SEM2, SEY2, and SEL1 and Facebook addiction item SNA16 have correlation coefficients $0.155,0.065,0.299$, and 0.204 , respectively, which do not meet the standard of $>0.30$. Thus, these four items were eliminated. Additionally, the remaining 46 items were kept on the official questionnaire for the next phase of the study. The coefficient " $\alpha$ " on the scale reaches 0.955 , indicating the scale has good consistency and high reliability.

The respondent's basic data, the five research variables of Facebook addiction, namely flow experience, enjoyment, concentration, interactivity, and self-traits (self-esteem, self-efficacy, and self-control), were included in the questionnaire. The final scales are listed in Table 1. The Likert-type scale, ranging from "Strongly disagree" to "Strongly agree," was used to measure various criteria. Answers were scored as 1 point for "Strongly disagree," 2 points for "Disagree," 3 for "Neutral," 4 for "Agree," and 5 for "Strongly agree." The higher the score was, the higher the level of agreement was, and vice versa. Finally, the study data were quantitatively analyzed using descriptive statistics, item discrimination analysis, reliability and validity analysis, structural equation modeling (SEM) estimation, and structural model analysis. SPSS version 20.0 was used to conduct the correlation analysis and t-tests. AMOS version 18.0 was used to verify the SEM structure. SEM analysis was conducted to determine the statistical significance of the research variables.

Table 1. Variables and questions index

\begin{tabular}{|c|c|c|c|}
\hline \multirow{2}{*}{$\begin{array}{c}\text { Variables } \\
\text { Facebook addiction }\end{array}$} & Questions & Literature & Index \\
\hline & $\begin{array}{l}\text { 1. I often fantasize about things on Facebook. } \\
\text { 2. I often fantasize about what my friends' latest statuses are } \\
\text { when I am not using Facebook. } \\
\text { 3. I feel nervous and irritable when I want to go on Facebook } \\
\text { but am unable to. } \\
\text { 4. I feel nervous and irritable when I am unable to use } \\
\text { Facebook for many days. } \\
\text { 5. I get in a bad mood and feel depressed when I am unable to } \\
\text { use Facebook, but these feelings disappear when I use } \\
\text { Facebook. } \\
\text { 6. I think about using Facebook in my sleep. } \\
\text { 7. I spend a lot of time on Facebook, ignoring trivial things in } \\
\text { life. } \\
\text { 8. I would rather sacrifice my sleep than miss using Facebook. } \\
\text { 9. I would rather be on Facebook than spend time with friends. } \\
\text { 10. The efficiency of my work (study) is affected when I spend } \\
\text { a lot of time on Facebook. } \\
\text { 11. I complain to the people around me that I spend too much } \\
\text { time on Facebook. } \\
\text { 12. I would rather spend time on Facebook than go out with }\end{array}$ & $\begin{array}{l}\text { Andreassen (2012) } \\
\text { Demetrovics et al. } \\
\text { (2008) }\end{array}$ & $\begin{array}{l}\text { SNA6 } \\
\text { SNA7 } \\
\text { SNA8 } \\
\text { SNA9 } \\
\text { SNA10 } \\
\text { SNA11 } \\
\text { SNA12 }\end{array}$ \\
\hline
\end{tabular}




\begin{tabular}{|c|c|c|c|}
\hline & $\begin{array}{l}\text { friends and family. } \\
\text { 13. I feel that I should reduce the time I spend on Facebook } \\
\text { and my frequency of Facebook use. }\end{array}$ & & SNA13 \\
\hline & $\begin{array}{l}\text { 14. I have tried to reduce the amount of time I spend on } \\
\text { Facebook, but have not succeeded. }\end{array}$ & & SNA14 \\
\hline & $\begin{array}{l}\text { 15. I have tried to hide the amount of time I spend on } \\
\text { Facebook. }\end{array}$ & & SNA15 \\
\hline & $\begin{array}{l}\text { 16. I persuade myself to stop in a couple of minutes when I am } \\
\text { on Facebook. }\end{array}$ & & SNA16 \\
\hline & $\begin{array}{l}\text { 17. I will seek the help of my Facebook friends when I run into } \\
\text { a problem on Facebook. }\end{array}$ & & SNA17 \\
\hline \multirow{4}{*}{$\begin{array}{c}\text { Flow } \\
\text { experience }\end{array}$} & 1. Many activities on Facebook stimulate my curiosity. & Pearce et al.(2005) & FLO1 \\
\hline & 2. When I am using Facebook, I think of nothing else. & & FLO2 \\
\hline & $\begin{array}{l}\text { 3. Time goes by very quickly when I am using } \\
\text { Facebook. }\end{array}$ & Chang \& Zhu (2012) & FLO3 \\
\hline & 4. I spend more time than I expect on Facebook. & & FLO4 \\
\hline \multirow[t]{4}{*}{ Enjoyment } & 1. I find that using Facebook is enjoyable. & Koufaris (2002) & ENM1 \\
\hline & 2. I like all the activities on Facebook. & Wang\&Hsiao(2012) & ENM2 \\
\hline & 3. I find that using Facebook makes me worry-free. & Hong et al.(2013) & ENM3 \\
\hline & $\begin{array}{l}\text { 4. Even if I run into difficulties on Facebook, I still enjoy } \\
\text { using it. }\end{array}$ & & ENM4 \\
\hline \multirow[t]{5}{*}{ Concentration } & 1. I feel a strong attraction to Facebook when I am using it. & Koufaris (2002) & CEN1 \\
\hline & 2. My attention is focused entirely on the activities on & Wang \&Hsiao (2012) & CEN2 \\
\hline & 3. I concentrate entirely on Facebook when using it. & & CEN3 \\
\hline & 4. I am completely immersed in Facebook activities. & & CEN4 \\
\hline & $\begin{array}{l}\text { 5. I am not disturbed by things around me when } \\
\text { I am using Facebook. }\end{array}$ & & CEN5 \\
\hline \multirow[t]{4}{*}{ Interactivity } & $\begin{array}{l}\text { 1. Facebook's interactive functions (messaging, community } \\
\text { discussions, and free call) meet my communication needs. }\end{array}$ & $\begin{array}{l}\text { Daft \& Lengel (1986) } \\
\text { Skadberg (2004) }\end{array}$ & INT1 \\
\hline & $\begin{array}{l}\text { 2. Facebook's interactive functions make it easy to express my } \\
\text { thoughts. }\end{array}$ & & INT2 \\
\hline & $\begin{array}{l}\text { 3. Facebook's built-in interactive functions (text and graphic } \\
\text { symbols) let me express myself freely. }\end{array}$ & & INT3 \\
\hline & $\begin{array}{l}\text { 4. Facebook has many channels for interaction, such as games } \\
\text { and information sharing. }\end{array}$ & & INT4 \\
\hline \multirow[t]{4}{*}{ Self-esteem } & 1. I feel I am a valuable member of society. & Scholz et al. (2002) & SEM1 \\
\hline & 2. I am proud of myself. & Tangney et al. (2004) & SEM2 \\
\hline & 3. I am an example for others to learn from. & Khang et al.(2013) & SEM3 \\
\hline & 4. I am popular among my friends. & & SEM4 \\
\hline \multirow[t]{4}{*}{ Self-efficacy } & $\begin{array}{l}\text { 1. I believe that as long as I work hard, I can overcome any } \\
\text { difficulty. }\end{array}$ & $\begin{array}{l}\text { Scholz et al. (2002) } \\
\text { Tangney et al. (2004) }\end{array}$ & SEY1 \\
\hline & 2. I believe I can deal with problems effectively. & Khang et al.(2013) & SEY2 \\
\hline & 3. I can stay calm and deal with problems when they arise. & & SEY3 \\
\hline & $\begin{array}{l}\text { 4. I am able to find multiple solutions to problems when they } \\
\text { arise. }\end{array}$ & & SEY4 \\
\hline \multirow[t]{4}{*}{ Self-control } & 1. I forget about what I should be doing when using Facebook. & Scholz et al. (2002) & SEL1 \\
\hline & 2. I think about other things when I am doing a task. & Tangney et al. (2004) & SEL2 \\
\hline & $\begin{array}{l}\text { 3. I often hinder others from completing what they are } \\
\text { supposed to be doing. }\end{array}$ & Khang et al.(2013) & SEL3 \\
\hline & 4. I keep making things worse even if I want to do it properly. & & SEL4 \\
\hline
\end{tabular}

\section{Study Results}

Of the 420 questionnaires collected, 401 were valid (response rate $=95.5 \%$ ). Nulty (2008) reported that online surveys that achieve a $43 \%$ response rate are considered adequate social related studies. The response rate of the online survey conducted in the present study was $86.4 \%$; if the response rate were $<43 \%$, we would have included the completed questionnaires of respondents without a Facebook account or of respondents with experience using some social networking site other than Facebook. In total, 284 participants (70.8\%) reported having continual access to Facebook for $>3$ years (Table 2), and 107 participants (26.7\%) had used it for 1-3 years. In all, $161(40.1 \%)$ participants spent $>3$ hours each day on Facebook, whereas merely 95 (23.7\%) participants spent $<1$ hour on it in a whole day (Table 2). In a normal person's daily schedule, sleep takes up 7-8 hours, school or work takes up 8-9 hours, meals and commuting takes up 2-3 hours, and the remaining time is for rest. In this study, we considered users spending $>2$ hours a day on Facebook to have a mild addiction, 2-3 hours to have a moderate addiction, and $>3$ hours to have a severe addiction. Only $43.4 \%$ (170) of the respondents were nonaddicts. Facebook addicts (especially those heavily addicted) use Facebook at any time, 
which affects their sleep, face-to-face communication, and effectiveness at work or school.

This study conducted a confirmatory factor analysis to examine the validity. Validity includes discriminant validity and convergent validity. The average variance extracted (AVE) method was used for discriminant validity. In Table 3, the values in the diagonal are the AVE square root values (enjoyment-to-concentration value) of each variable; the rest were subjected to Pearson analysis using SPSS tools. If the AVE square root on the diagonal line is $<0.85$, then that variable has discriminant validity (Hair et al., 2015). The correlation between each variable is no more than 0.85 , which means there is no collinearity (Table 3). The AVE square root of each variable is more than all related coefficients; hence, they are in accordance with theoretical standards. This study has discriminant validity.

Convergent validity was used to test whether all the observed variables in a construct converge to a latent variable. Hair et al. (2015) pointed out that a variable must conform to three criteria to have convergent validity, namely (1) factor loading $\geq 0.7$ (>0.6 is acceptable); (2) CR $\geq 0.7$; and (3) AVE $>0.5$. Additionally, Stevanovic et al. (2013) emphasized that Cronbach's $\alpha$ values should be $>0.6$ for constructs to be considered as showing an acceptable level of convergent validity. The results of this study show that most of the factor loadings of flow experience, enjoyment, concentration, interactive, self-traits, and Facebook addiction were $>0.7$; the remaining three loadings in either flow experience or Facebook addiction were still >0.6. Additionally, CR, AVE, and Cronbach's $\alpha$ of each construct were greater than $0.7,0.5$, and 0.8 , respectively (Table 4). Therefore, these test results indicate that the constructs of this study exhibited favorable convergent validity.

Table 2. Descriptive statistics

\begin{tabular}{|c|c|c|c|}
\hline Variable & Category & Number & $\%$ \\
\hline \multirow[t]{2}{*}{ Type of participants } & Never married & 363 & 90.5 \\
\hline & Divorced & 38 & 9.5 \\
\hline \multirow{2}{*}{ Gender } & Man & 236 & 58.8 \\
\hline & Woman & 165 & 41.2 \\
\hline \multirow{8}{*}{ Age } & $\leq 20$ & 38 & 9.5 \\
\hline & $21-25$ & 130 & 32.4 \\
\hline & $26-30$ & 136 & 33.9 \\
\hline & $31-35$ & 42 & 10.5 \\
\hline & $36-40$ & 30 & 7.5 \\
\hline & $41-45$ & 8 & 2.0 \\
\hline & $46-50$ & 8 & 2.0 \\
\hline & $\geq 51$ & 9 & 2.2 \\
\hline \multirow{4}{*}{ Education level } & Junior High School & 9 & 2.2 \\
\hline & High School & 30 & 7.4 \\
\hline & University & 272 & 68.0 \\
\hline & Postgraduate & 90 & 22.4 \\
\hline \multirow{4}{*}{ How long have you accessed Facebook? } & $1-6$ months & 4 & 1.0 \\
\hline & $6-12$ months & 6 & 1.5 \\
\hline & $1-3$ years & 107 & 26.7 \\
\hline & $\geq 3$ years & 284 & 70.8 \\
\hline \multirow{6}{*}{$\begin{array}{l}\text { How often do you access Facebook every } \\
\text { day? }\end{array}$} & Within $0.5 \mathrm{hr}$ & 28 & 7.0 \\
\hline & $0.5-1 \mathrm{hr}$ & 67 & 16.7 \\
\hline & $1-2 \mathrm{hr}$ & 75 & 18.7 \\
\hline & $2-3 \mathrm{hr}$ & 70 & 17.5 \\
\hline & $3-4 \mathrm{hr}$ & 72 & 18.0 \\
\hline & $\geq 4 \mathrm{hr}$ & 89 & 22.2 \\
\hline \multirow{6}{*}{$\begin{array}{l}\text { What is your main purpose to access } \\
\text { Facebook? }\end{array}$} & Look for a date & 26 & 6.5 \\
\hline & Find a Mr. Right or Ms. Right & 25 & 6.2 \\
\hline & Learn about friends' recent status & 100 & 24.9 \\
\hline & Build (maintain) a relationship & 64 & 16.0 \\
\hline & Record your life & 160 & 39.9 \\
\hline & Get the information you want & 26 & 6.5 \\
\hline
\end{tabular}


Table 3. Results of discriminant validity

\begin{tabular}{ccccccc}
\hline Construct & Enjoyment & Concentration & Interactivity & Self-traits & $\begin{array}{c}\text { Flow } \\
\text { experience }\end{array}$ & $\begin{array}{c}\text { Facebook } \\
\text { addiction }\end{array}$ \\
\hline Enjoyment & $\mathbf{0 . 8 4 0}$ & & & & & \\
Concentration & 0.291 & $\mathbf{0 . 8 0 6}$ & & & & \\
Interactivity & 0.258 & 0.201 & $\mathbf{0 . 7 7 5}$ & & & \\
Self-traits & 0.162 & 0.146 & 0.259 & $\mathbf{0 . 7 8 1}$ & & \\
Flow experience & 0.255 & 0.187 & 0.994 & 0.257 & $\mathbf{0 . 7 1 1}$ & $\mathbf{0 . 7 9 7}$ \\
Facebook & 0.319 & 0.332 & 0.350 & 0.280 & 0.338 & \\
addiction & & & & & & \\
\hline
\end{tabular}

Note. Diagonal values are the AVE values of each construct. The remaining values are $\mathrm{R}^{2}$ values.

Table 4. Results of convergent validity

\begin{tabular}{|c|c|c|c|c|}
\hline Factor & Standard loading & $\mathrm{CR}$ & AVE & Cronbach's $\alpha$ \\
\hline \multirow{4}{*}{ Enjoyment } & 0.820 & \multirow{4}{*}{0.906} & \multirow{4}{*}{0.706} & \multirow{4}{*}{0.856} \\
\hline & 0.840 & & & \\
\hline & 0.860 & & & \\
\hline & 0.840 & & & \\
\hline \multirow{5}{*}{ Concentration } & 0.780 & \multirow{5}{*}{0.903} & \multirow{5}{*}{0.650} & \multirow{5}{*}{0.902} \\
\hline & 0.820 & & & \\
\hline & 0.810 & & & \\
\hline & 0.810 & & & \\
\hline & 0.810 & & & \\
\hline \multirow{4}{*}{ Interactivity } & 0.710 & \multirow{4}{*}{0.858} & \multirow{4}{*}{0.602} & \multirow{4}{*}{0.903} \\
\hline & 0.810 & & & \\
\hline & 0.790 & & & \\
\hline & 0.790 & & & \\
\hline \multirow{3}{*}{ Self-traits } & 0.730 & \multirow{3}{*}{0.824} & \multirow{3}{*}{0.610} & \multirow{3}{*}{0.825} \\
\hline & 0.780 & & & \\
\hline & 0.830 & & & \\
\hline \multirow{4}{*}{ Flow experience } & 0.770 & \multirow{4}{*}{0.802} & \multirow{4}{*}{0.505} & \multirow{4}{*}{0.800} \\
\hline & 0.650 & & & \\
\hline & 0.780 & & & \\
\hline & 0.630 & & & \\
\hline \multirow{4}{*}{ Facebook addiction } & 0.640 & \multirow{4}{*}{0.874} & \multirow{4}{*}{0.636} & \multirow{4}{*}{0.870} \\
\hline & 0.820 & & & \\
\hline & 0.880 & & & \\
\hline & 0.830 & & & \\
\hline
\end{tabular}

Byrne (1998) affirmed that a favorable model fit is necessary to verify a research framework through SEM. The overall model fit indicators proposed by Hair et al. (2015) and Byrne (1998) were adopted in this study, and the results show that the absolute fit indicators, incremental fit indicators, and simplified fit indicators of the study model fulfill the standard requirements. Regarding the absolute fit indicators, the $\mathrm{p}$ value of the chi-squared test $(\chi 2$ test) was $p=0.000$ (not $>0.05$ ), the root mean square residual (RMR) was $0.066(<0.08)$, the root mean square error of approximation (RMSEA) was $0.031(<0.08)$, the goodness-of-fit index (GFI) was $0.940(>0.90)$, and the adjusted GFI was 0.920 (> 0.90). Regarding the incremental fit indicators, the normed fit index (NFI) was 0.941 (> 0.90), the relative fit index (RFI) was 0.928 (> 0.90), the incremental fit index (IFI) was 0.983 (> 0.90), nonnormed fit index (NNFI)/ Tucker-Lewis index (TFI) was $0.983(>0.90)$, and the comparative fit index (CFI) was $0.994(>0.90)$. Finally, regarding the simplified fit indicators, the parsimonious GFI was 0.702 (> $0.50)$, the parsimonious NFI was $0.764(>0.50)$, and the critical $\mathrm{N}$ was $334(>200)$. To this stage, the study model did not achieve a favorable statistical fit probably because the p value of the chi-squared test is unqualified.

Bagozzi and Yi (1988) and Oishi (2007) have emphasized that chi-squared test is not an ideal overall fit index for psychology research because it is sensitive to the sample size. When the sample size is very large (e.g. 1,000) or very small, the distribution of key variables is skewed. Bagozzi and Yi (1988) suggested using the ratio of chi-squares to degrees of freedom (i.e. normed chi-squares) to replace the chi-squared test for verification of model fit. They also recommended that the ratio should be between 1 and 5 , preferably $<3$. The $\chi 2 /$ df value obtained in this study model was 1.390 (Table 5), which indicates its goodness to fit is acceptable. Due to the large number of variables, this research had > 200 samples; hence, the Bollen-Stine bootstrap p-value correction method was added. Using a normal $\chi 2$ value distribution, estimated using Bollen-Stine bootstrapping with a distribution of 1,000 values, the mean value was 268.96, which was 252.08 less than the value calculated using the maximum likelihood method (521.04). Therefore, the model was modified. Using bootstrapping to estimate 
the mean $\chi^{2}$ and then dividing by $243 \mathrm{df}$, we get $\chi^{2} / \mathrm{df}=1.107$ (due to the special characteristics of the $\chi^{2}$ value; because there are more than $100 \mathrm{df}$ and the $\mathrm{p}$ values are $<0.05$, it was not necessary to recalculate the value). After corrections were made, the goodness-of-fit indices met the established standards (Table 6). The BollenStine $\mathrm{p}$ correction $\chi^{2}$ value appears to be nonsignificant, and the index is good; thus, the initial significant $\chi^{2}$ value was obtained because of the number of samples. This study also tested the latent path coefficients of each construct. The results reveal that most of the standardized regression weighting coefficients (path coefficients) of the overall model were statistically significant $(\mathrm{p}<0.05)$, except the relationship between enjoyment and flow experience. Particularly, concentration and interactivity exerted positive effects on flow experience. Self-trait and its subfactors (self-esteem, self-efficacy, and self-control) individually had a positive effect on flow experience and Facebook addiction. Additionally, the standardized regression coefficients between the latent variables represent the direct effect of the latent variables. Therefore, the standardized regression coefficients in Table 7 represent the path coefficients of the latent constructs; overall, the 11 hypotheses proposed in this study were supported and 1 hypothesis was unsupported.

Table 5. Statistical fit of the overall model in SEM test

\begin{tabular}{llllc}
\hline Indicator & & $\begin{array}{c}\text { Standard } \\
\text { requirement }\end{array}$ & Test result & Outcome \\
\hline Absolute fit indicator & $\chi^{2}$ test & $p>0.05$ & $\mathrm{p}=0.000$ & Unqualified \\
& RMR & $<0.08$ & 0.066 & OK \\
& RMSEA & $<0.08$ & 0.031 & OK \\
& GFI & $>0.90$ & 0.940 & OK \\
& AGFI & $>0.90$ & 0.920 & OK \\
\hline Incremental fit indicator & NFI & $>0.90$ & 0.941 & OK \\
& RFI & $>0.90$ & 0.928 & OK \\
& IFI & $>0.90$ & 0.983 & OK \\
& NNFI/TFI & $>0.90$ & 0.983 & OK \\
& CFI & $>0.90$ & 0.983 & OK \\
\hline Simplified fit indicator & PGFI & $>0.50$ & 0.702 & OK \\
& PNFI & $>0.50$ & 0.764 & OK \\
& PCFI & $>0.50$ & 0.797 & OK \\
& Critical N & $>200$ & 334 & OK \\
\hline
\end{tabular}

Table 6. Bollen-Stine p correction

\begin{tabular}{ccc}
\hline Fit indices & Criteria & Bollen-Stine p correction \\
\hline$\chi^{2}$-statistic & Nonsignificant & Nonsignificant \\
$\chi^{2} / \mathrm{df}$ & $<3$ & 1.107 \\
CFI & $>0.9$ & 0.995 \\
SRMR & $<0.08(\mathrm{CFI}>0.92)$ & 0.941 \\
RMSEA & $<0.07(\mathrm{CFI} \geq 0.9)$ & 0.016 \\
GFI & $>0.9$ & 0.949 \\
AGFI & $>0.8$ & 0.923 \\
\hline
\end{tabular}

Table 7. Path analysis for SEM test

\begin{tabular}{lccccc}
\hline Hypothesis & Estimate & $\mathrm{SE}$ & $\mathrm{CR}$ & $\mathrm{p}$ & $\begin{array}{c}\text { Hypothesis } \\
\text { supported }\end{array}$ \\
\hline Enjoyment--> flow experience & 0.029 & 0.017 & 1.733 & 0.083 & $\mathrm{X}$ \\
Concentration--> flow experience & 0.038 & 0.017 & 2.220 & $*$ & $\mathrm{O}$ \\
Interactivity--> flow experience & 0.067 & 0.021 & 3.171 & $* *$ & $\mathrm{O}$ \\
Self-traits--> flow experience & 0.270 & 0.067 & 4.045 & $* * *$ & $\mathrm{O}$ \\
Self-esteem--> flow experience & 0.731 & 0.220 & 15.512 & $* * *$ & $\mathrm{O}$ \\
Self-efficacy--> flow experience & 0.782 & 0.217 & 16.737 & $* * *$ & $\mathrm{O}$ \\
Self-control--> flow experience & 0.833 & 0.218 & 18.060 & $* * *$ & $\mathrm{O}$ \\
Self-traits--> Facebook addiction & 0.239 & 0.066 & 3.635 & $* * *$ & $\mathrm{O}$ \\
Self-esteem--> Facebook addiction & 0.731 & 0.220 & 15.512 & $* * *$ & $\mathrm{O}$ \\
Self-efficacy--> Facebook addiction & 0.782 & 0.217 & 16.737 & $* * *$ & $\mathrm{O}$ \\
Self-control--> Facebook addiction & 0.833 & 0.218 & 18.060 & $* * *$ & $\mathrm{O}$ \\
Flow experience--> Facebook addiction & 0.351 & 0.062 & 5.631 & $* * *$ & $\mathrm{O}$ \\
\hline
\end{tabular}

$* \mathrm{p}<0.05 ; * * \mathrm{p}<0.01 ; * * * \mathrm{p}<0.001$ 


\section{Discussion}

In contrast to previous studies (J. C. Hong et al., 2013; Merhi, 2016), this study showed no significant positive correlation between the antecedents of enjoyment and flow experience. Combining the definition of enjoyment from Davies et al. (1992) ("the extent to which the activity of using the technology is perceived to be enjoyable in its own right, apart from any performance consequences that may be anticipated") and the perception put forward by Koufaris (2002), enjoyment refers to a user's internal enjoyment of activities; when there is a shift from a non-spontaneous to a spontaneous activity, flow experience is achieved. Facebook, a social networking site, which involves using technology, does not seem to be an enjoyable activity for respondents. The demographic data in Table 2 somewhat confirms this. Most respondents use Facebook to record their lives or find out what their friends are up to. These young people do not visit Facebook for finding a date or life partner and hence do not experience flow caused by enjoyment.

The results of this study show a significant positive correlation between concentration and flow experience as well as between interactivity and flow experience. The study of Pearce et al. (2005) on online learning behavior demonstrated that the more the students concentrate on an online learning model, the higher is the degree of learning immersion leading to flow experience. Interesting online learning processes and methods that differ from other learning methods encourage immersion in students. This study was based on the flow experience of Facebook users who access Facebook using mobile devices and the results are consistent with previous online studies. Thus, flow is generated if one is sufficiently focused irrespective of whether a desktop computer or a mobile device is used.

Similarly, users easily experience flow if the Internet can provide sufficient interaction. However, previous researchers have focused on whether a website's design can provide sufficient human-computer interaction (Skadberg \& Kimmel, 2004; Webster \& Martocchio, 1992). Interactivity on Facebook goes further than humancomputer interaction because it encompasses interaction between Facebook users. Therefore, concentration and interactivity lead to user immersion or addiction. The more users focus on an activity or interaction on Facebook, the more likely they are to become immersed or addicted. Thus, many users become addicted and continue to focus on what their friends and those they are following are posting.

This study found a significant correlation between Facebook addiction and the influence of self-traits on Facebook users. In a study on addiction of mobile phones, Khang et al. (2012) discovered that the three observable self-traits resulted in a higher or lower influence on addiction. Those with lower self-traits have a higher risk of addiction. Khang et al. (2013) points out that the lower the self-trait is, the greater the chances of becoming addicted are; this was especially prevalent in those with low self-control. In this study, the CR values of the three observable variables self-esteem, self-efficacy, and self-control were 15.512, 16.737, and 18.060, respectively (Table 7). Results for self-control were the most significant. Thus, the lower the user's self-control was, the greater was the likelihood of immersion or addiction. This finding is consistent with that of Khang et al. (2013). Although the data for this study were collected through Internet surveys, most respondents were between 16 and 30 years of age (Table 2). Moreover, apart from the research subject and Facebook usage, this age group may be more prone to low self-control and self-regulation.

In addition, Facebook's user interface and interactive mode also provide a new channel of communication between users, which is more convenient and interactive than instant messaging and email. The ability to record one's life and click on "like" on friends' comments makes many users love Facebook. The user's new posts make up a dynamic feed; "likes" on their posts indicate that they are receiving praise from their friends and they are popular in their circle of friends, leading to a high level of happiness. But this process seems different from the enjoyment of accumulating flow experience. Thus, the experience of a user who is immersed in comparable hobbies gradually shifts from concentration or immersion to addiction and many users cannot get away from them.

Kim (2006), Park, \& Hwang (2009), and Khang et al. (2013) have found a positive correlation between flow experience and addiction in their studies on immersion and addiction to video games and smart devices. They have pointed out that continual immersion in an activity gradually leads to addiction. This was applied to the study of Facebook; the results were similar to the aforementioned findings (Table 7). Table 2 shows that 95.7\% of the respondents used Facebook for more than a year; 57.6\% of the moderate and severe addicts used Facebook for $>2$ hours a day. Hence, this means respondents have been addicted for more than a year probably cannot be explained by the flow theory. Flow theory emphasizes that beginners should accumulate flow experience through enjoyment, concentration, and interactivity, and a theory of quit experience needs to be developed so these young addicts reduce their Facebook use and return to face-to-face social life. 


\section{Conclusions}

Several studies have been conducted on Facebook addiction from the standpoint of management or psychology, and the BFAS and OSS were developed to measure user addiction. However, the number of studies that use the DFAS to measure addiction is still in the minority. The study found that the enjoyment factor, which allows users to accumulate flow experience, which exists on regular websites or social sites, is nonexistent on Facebook. Instead, concentration and the interaction created between users are what create flow experience in unmarried users and make them addicted. Users who have less self-control are more likely to become addicted to Facebook. Therefore, discouraging users from long periods of Facebook use at multiple times every day and leading them back to contact real people, including dating and finding a life partner, will be an essential direction for future research. In addition, checking the direct relationship between enjoyment and Facebook addiction by a suitable statistical methods might be interesting. If the positive relationship is significant, then there might be a construct overlap between enjoyment and flow experience. When conducting a mediation analysis to test the mediation effect of flow experience between self-traits and Facebook addiction, as well as the mediating effect of flow experience between interactivity (concentration) and Facebook addiction. It will be suitable for in-depth analysis when flow experience acts as a mediator in a psychological mechanism, whether both social value (the interactivity) and individual hedonic value (concentration) will form addiction behavior? Finally, it might also be interesting to check the moderating effect of self-control, self-efficacy, and self-esteem on the positive relationship between flow experience and FB addiction, seeing if high level (versus low level) of self-control (or self-esteem/self-efficacy) will weaken the positive association between flow experience and addiction behavior. If the moderating effect exits, then this study would prove some practical implication for solving Facebook addiction problem.

\section{References}

Adamic, L. A., \& Adar, E. (2003). Friends and neighbors on the web. Social Networks, 25(3), 211-230. https://doi.org/10.1016/S0378-8733(03)00009-1

Andreassen, C. S., et al. (2012). Development of a facebook addiction scale. Psychological Reports, 110(2), 501-517. https://doi.org/10.2466/02.09.18.PR0.110.2.501-517

Bagozzi, R. P., \& Yi, Y. (1988). On the evaluation of structural equation models. Journal of the Academy of Maketing Science, 16(1), 74-94. https://doi.org/10.1007/BF02723327

Bandura, A. (1997). Self-efficacy: The exercise of control. New York: Freeman.

Barnes, J. A. (1954). Class and committees in a Norwegian island parish. Human Relations, 7(1), 39-58. https://doi.org/10.1177/001872675400700102

Baumeister, R. F. (1999). The nature and structure of the self: an overview, the self in social psychology. In R. Baymeister (Ed.), The self in social psychology. Philadelphia, PA: Psychology Press

Brown, J. D. (1993). Motivational conflict and the self: the double-bind of low self-esteem. In R. F. Baumeister (Ed.), Self-Esteem: The Puzzle of Low Self-Regard (pp. 117-130). Boston, MA: Springer US. https://doi.org/10.1007/978-1-4684-8956-9_6

Bruning, R. H., et al. (2010). Cognitive psychology and instruction (5th ed.). Columbus, OH: Prentice-Hall.

Byrne, B. M. (1998). Structural equation modeling with LISREL,PRELIS and SIM-PLIS: Basic concepts, applications and programming. New York: Psychology Press.

Chang, Y. P., \& Zhu, D. H. (2012). The role of perceived social capital and flow experience in building users' continuance intention to social networking sites in China. Computers in Human Behavior, 28(3), 995-1001. https://doi.org/10.1016/j.chb.2012.01.001

Choi, D. H., et al. (2007). ERP training with a web-based electronic learning system: the flow theory perspective. International Journal of Human-Computer Studies, 65(3), 223-243. https://doi.org/10.1016/j.ijhcs.2006.10.002

Csikszentmihalyi, M. (1975). Beyond boredom and anxiety. San Francisco, CA: Jossey-Bass.

Csikszentmihalyi, M. (1990). Flow:the psychology of optimal experience. New York: Harpers Perennial.

Csikszentmihalyi, M., \& Massimini, F. (1985). On the psychological selection of biocultural information. New Ideas in Psychology, 3(2), 115-138. https://doi.org/10.1016/0732-118X(85)90002-9

Csikszentmihalyi, M., \& Nakamura, J. (2010). Effortless attention in everyday life: A systematic phenomenology. In B. Bruya (Ed.), Effortless Attention: A New Perspective in the Cognitive Science of Attention and Action 
(pp. 179--189): MIT Press. https://doi.org/10.7551/mitpress/9780262013840.003.0009

Daft, R. L., \& Lengel, R. H. (1986). Organizational information requirements, media richness and structural design. Management Science, 32(5), 554-571. https://doi.org/10.1287/mnsc.32.5.554

Davies, F. D., et al. (1992). Extrinsic and Intrinsic motivation to use computers in the workplace. Journal of Applied Social Psychology, 22, 1111-1132. https://doi.org/10.1111/j.1559-1816.1992.tb00945.x

de Manzano, Ö., et al. (2013). Individual differences in the proneness to have flow experiences are linked to dopamine D2-receptor availability in the dorsal striatum. NeuroImage, 67, 1-6. https://doi.org/10.1016/j.neuroimage.2012.10.072

Demetrovics, Z., et al. (2008). The three-factor model of Internet addiction: the development of the problematic internet use questionnaire. Behavior Research Methods, 40(2), 563-574. https://doi.org/10.3758/BRM.40.2.563

Dewald, J. F., et al. (2010). The influence of sleep quality, sleep duration and sleepiness on school performance in children and adolescents: a meta-analytic review. Sleep Medicine Reviews, 14(3), 179-189. https://doi.org/10.1016/j.smrv.2009.10.004

Echeburúa, E., \& de Corral, P. (2010). Addiction to new technologies and to online social networking in young people: a new challenge. Adicciones, 22(2), 91-95. https://doi.org/10.20882/adicciones.196

Esteban-Millat, I., et al. (2014). Modelling students' flow experiences in an online learning environment. Computers \& Education, 71, 111-123. https://doi.org/10.1016/j.compedu.2013.09.012

Gentile, D. A., et al. (2017). Internet Gaming Disorder in Children and Adolescents. Pediatrics, 140(Supplement 2), S81-S85. https://doi.org/10.1542/peds.2016-1758H

Gist, M. E., \& Mitchell, T. R. (1992). Self-efficacy: a theoretical analysis of its determinants and malleability. The Academy of Management Review, 17(2), 183-211. https://doi.org/10.5465/amr.1992.4279530

Golbeck, J. (2005). Computing and applying trust in web-based social networks. (Ph.D.), University of Maryland, MD, USA.

Gonidis, L., \& Sharma, D. (2017). Internet and Facebook related images affect the perception of time. Journal of Applied Social Psychology, 47(4), 224-231. https://doi.org/10.1111/jasp.12429

Griffiths, M. (2000). Internet addiction-time to be taken seriously? Addiction Research, 8(5), 413-418. https://doi.org/10.3109/16066350009005587

Hair, J. F., et al. (2015). Multivariate data analysis (7th ed.). Upper Saddle River, NJ: Prentic Hall.

Hoffman, D. L., \& Novak, T. P. (2009). Flow online: lessons learned and future prospects. Journal of Interactive Marketing, 23(1), 23-34. https://doi.org/10.1016/j.intmar.2008.10.003

Hong, F. Y., et al. (2014). Analysis of the psychological traits, Facebook usage, and Facebook addiction model of Taiwanese university students. Telematics and Informatics, 31, 597-606. https://doi.org/10.1016/j.tele.2014.01.001

Hong, J. C., et al. (2013). Comparing the retention and flow experience in playing solitary and heart attack games of San Zi Jing: a perspective of dual process theory. Computers \& Education, 69, 369-376. https://doi.org/10.1016/j.compedu.2013.07.027

Karaiskos, D., et al. (2010). Social network addiction: a new clinical disorder? European Psychiatry, 25(supplement 1), 855. https://doi.org/10.1016/S0924-9338(10)70846-4

Kernis, M. H. (1993). The roles of stability and level of self-esteem in psychological functioning. In R. F. Baumeister (Ed.), Self-Esteem: The Puzzle of Low Self-Regard (pp. 167-182). Boston, MA: Springer US. https://doi.org/10.1007/978-1-4684-8956-9_9

Khang, H. K., et al. (2013). Self-traits and motivations as antecedents of digital media flow and addiction: the Internet, mobile phones, and video games. Computers in Human Behavior, 29(6), 2416-2424. https://doi.org/10.1016/j.chb.2013.05.027

Khang, H. K., et al. (2012). Self as an antecedent of mobile phone addiction. International Journal of Mobile Communications, 10(1), 65-84. https://doi.org/10.1504/JJMC.2012.044523

Kim, B. (2006). An exploratory study of an excessive reliance on digital devices. KADO Issue Report, 3(6), $1-36$. 
Kim, H. K., \& Davis, K. E. (2009). Toward a comprehensive theory of problematic internet use: evaluating the role of self-esteem, anxiety, flow, and the self-rated importance of Internet activities. Computers in Human Behavior, 25(2), 490-500. https://doi.org/10.1016/j.chb.2008.11.001

Koc, M., \& Gulyagci, S. (2013). Facebook addiction among Turkish college students: The role of psychological health, demographic, and usage characteristics. Cyberpsychology, Behavior, and Social Networking, 16(4), 279-284. https://doi.org/10.1089/cyber.2012.0249

Koufaris, M. (2002). Applying the technology acceptance model and flow theory to online consumer behavior. Information Systems Research, 13(2), 205-223. https://doi.org/10.1287/isre.13.2.205.83

Kuss, D. J., \& Griffiths, M. (2011). Online social networking and addiction-a review of the psychological literature. International Journal of Enviornmental Research and Public Health, 8(9), 3528-3552. https://doi.org/10.3390/ijerph8093528

La Barbera, D., et al. (2009). Social network and addiction. Annual Review of Cybertherapy and Telemedicine, 7 , 33-36.

Luchini, K. (2015). The Social Network. Retrieved from https://prezi.com/9uajwns4j0ln/the-social-network/

Maibach, E., \& Murphu, D. A. (1995). Self-efficacy in health promotion research and practice: conceptualization and measurement. Health Education Research, 10(1), 37-50. https://doi.org/10.1093/her/10.1.37

Merhi, M. I. (2016). Towards a framework for online game adoption. Computers in Human Behavior, 60, 253-263. https://doi.org/10.1016/j.chb.2016.02.072

Mosing, M. A., et al. (2012). Genetic and Environmental Influences on the Relationship between Flow Proneness, Locus of Control and Behavioral Inhibition. PLos One, 7(11), e47958. https://doi.org/10.1371/journal.pone.0047958

Novak, T. P., \& Hoffman, D. L. (1998). Modeling the structure of the flow experience among web users. Paper presented at the INFORMS Marketing Science and the Internet Mini-Conference, Cambridge, MA.

Nulty, D. D. (2008). The adequacy of response rates to online and paper surveys: what can be done? Assessment \&Evaluation in Higher Education, 33(3), 301-314. https://doi.org/10.1080/02602930701293231

Oishi, S. (2007). The application of structural equation modeling and item response theory to cross-cultural positive psychology research. In A. D. Ong \& M. H. van Dulmen (Eds.), Oxford Handbook of Methods in Positive Psychology (pp. 126-138). Oxford, UK: Oxford Univesity Press.

Park, S., \& Hwang, H. S. (2009). Understanding online game addiction: connection between presence and flow. In J. J.A. (Ed.), Human-Computer Interaction. Interacting in Various Application Domains (Vol. 5613, pp. 378-386). Berlin, Heidelberg: Springer.

Pearce, J. M., et al. (2005). The ebb and flow of online learning. Computers in Human Behavior, 21(5), 745-771. https://doi.org/10.1016/S0747-5632(04)00036-6

Pelling, E. L. (2009). The theory of pianned behavior appiied to young peopie's use of sociai networkting web sites. Cyberpsychology \& Behavior, 12(6), 755-759. https://doi.org/10.1089/cpb.2009.0109

Rosenberg, M. (1965). Society and the adolescent self-image. Princeton: Princetin University Press. https://doi.org/10.1515/9781400876136

Scholz, U., et al. (2002). Is general self-efficacy a universal construct? psychometric findings from 25 countries. European Journal of Psychological Assessment, 18(3), 242-251. https://doi.org/10.1027//1015-5759.18.3.242

Siekpe, J. S. (2005). An examination of the multidimensionality of flow construct in a computer-mediated environment. Journal of Electronic Commerce Research, 6(1), 31-43.

Skadberg, T. X., \& Kimmel, J. R. (2004). Visitors' flow experience while browsing a web site: its measurement, contributing factors. Computers in Human Behavior, 20(3), 403-422. https://doi.org/10.1016/S0747-5632(03)00050-5

Sledgianowski, D., \& Kulviwat, S. (2009). Using social network sites: the effects of playfulness, critical mass and trust in a hedonic context. Journal of Computer Information Systems, 49(4), 74-83.

Steuer, J. (1992). Defining virtual reality: dimensions determining telepresence. Journal of Communication, 42(4), 73-93. https://doi.org/10.1111/j.1460-2466.1992.tb00812.x 
Stevanovic, D., et al. (2013). Evaluating the serbian version of the KIDSCREEN quality-of-life questionnaires: reliability, validity, and agreement between children's and parents' ratings. Quality of Life Research, 22(7), 1729-1737. https://doi.org/10.1007/s11136-012-0286-4

$\mathrm{Su}$, Y. S., et al. (2016). The effect of flow experience on player loyalty in mobile game application. Computers in Human Behavior, 63, 240-248. https://doi.org/10.1016/j.chb.2016.05.049

Tangney, J. P., et al. (2004). High self-control predicts good adjustment, less pathology, better grades, and interpersonal success. Journal of Personality, 72(2), 271-324.

https://doi.org/10.1111/j.0022-3506.2004.00263.x

Ullén, F., et al. (2012). Proneness for psychological flow in everyday life: associations with personality and intelligence. Personality and Individual Differences, 52(2), 167-172. https://doi.org/10.1016/j.paid.2011.10.003

Un, C. A., et al. (2010). R\&D collaborations and product innovation. Journal of Product Innovation Management, 27(5), 673-689. https://doi.org/10.1111/j.1540-5885.2010.00744.x

Wang, L. C., \& Hsiao, D. F. (2012). Antecedents of flow in retail store shopping. Journal of Retailing and Consumer Services, 19(4), 381-389. https://doi.org/10.1016/j.jretconser.2012.03.002

Webster, J., \& Martocchio, J. J. (1992). Microcomputer playfulness: development of a measure with workplace implications. MIS Quarterly, 16(2), 201-226. https://doi.org/10.2307/249576

Wilson, K., et al. (2010). Psychoiogicai predictors of young adults' use of social networking sites. Cyberpsychology, Behavior, and Social Networking, 13(2), 173-177. https://doi.org/10.1089/cyber.2009.0094

Yang, S., et al. (2014). The benefits and dangers of flow experience in high school students' internet usage: The role of parental support. Computers in Human Behavior, 41, 504-513.

https://doi.org/10.1016/j.chb.2014.09.039

Zimmerman, B. J. (2000). Self-efficacy: an essential motive to learn. Contemporary Educational Psychology, 25(1), 82-91. https://doi.org/10.1006/ceps.1999.1016

\section{Copyrights}

Copyright for this article is retained by the author(s), with first publication rights granted to the journal.

This is an open-access article distributed under the terms and conditions of the Creative Commons Attribution license (http://creativecommons.org/licenses/by/4.0/). 